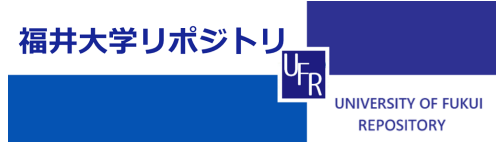

Devel opment of Anonymous Net works Based on Symmetric Key Encrypti ons

\begin{tabular}{|l|l|}
\hline 著者 & $\begin{array}{l}\text { HADDAD Hazi m TAMRA Shi nsuke, TAN GUCH } \\
\text { Shuj i , YANASE Tat sur o }\end{array}$ \\
\hline $\begin{array}{l}\text { j our nal or } \\
\text { publ i cat i on ti t l e }\end{array}$ & JOURNAL OF NETWORKS \\
\hline vol une & 6 \\
\hline number & 11 \\
\hline page $\mathrm{r}$ ange & 1533 - 1542 \\
\hline year & $2011-11$ \\
\hline URL & ht $\mathrm{t}$ : //hdl . handl e. net /10098/4850 \\
\hline
\end{tabular}




\title{
Development of Anonymous Networks Based on Symmetric Key Encryptions
}

\author{
Hazim Haddad \\ University of Fukui, Fukui, Japan \\ Email: hazimhaddad@yahoo.com \\ Shinsuke Tamura, Shuji Taniguchi and Tatsuro Yanase \\ University of Fukui, Fukui, Japan \\ Email: \{tamura, stamigut, yanase $\}$ u-fukui.ac.jp
}

\begin{abstract}
Anonymous networks enable entities to send messages without disclosing their identities. Many anonymous networks had been proposed already, such as Mixnet, DC-net, Crowds, etc., however, they still have serious drawbacks. Namely, they require tremendous computation overheads to transmit messages over networks. That is because asymmetric key encryption algorithms are used. This paper proposes ESEBM (Enhanced Symmetric Key Encryption based Mixnet), a new mechanism for anonymous communication that removes drawbacks of existing anonymous networks while exploiting symmetric key encryption algorithms. According to experimentations, throughput of ESEBM is about 1/4.4 of usual non-anonymous networks, and it achieves more than 36 times higher throughput compared with Mixnet. In addition, different from existing anonymous networks, ESEBM can handle reply messages without any additional mechanism, and it can protect itself from various threats, e.g. DOS attacks and message forgeries.
\end{abstract}

Index Terms - anonymous communication, mixnet, privacy protection, symmetric key encryption algorithm

\section{INTRODUCTION}

Identities of message senders are sometimes as sensitive as messages themselves. For example, a company may acquire highly confidential information about its rival companies from identities of their customers and suppliers. Therefore, the importance of anonymous communication is increasing as more people are being involved in network based communication. Anonymous networks are ones that enable message senders to send their messages without disclosing their identities, and various anonymous networks had been proposed already, e.g. Mix net [1, 5, 9], DC-net [2], Crowds [4], etc., to protect secrets of entities that communicate through networks. However, they still have serious drawbacks. For example, although Mix net is one of the most promising mechanisms, it requires the tremendous amount of computations to encrypt/decrypt messages that are forwarded from senders to their receivers. That is because asymmetric key

* Graduate School of Engineering, University of Fukui 3-9-1, Bunkyo, Fukui 910-8507, Japan encryption/decryption functions are adopted. In this paper, a new anonymous network ESEBM (Enhanced Symmetric Key Encryption based Mix net) is proposed that removes drawbacks of existing anonymous networks by using symmetric key encryption functions.

ESEBM consists of two parts, they are the $\mathrm{CP}$ generator (offline) and the anonymous channel (online) each of which is configured as a sequence of servers, and senders obtain secret keys of individual servers in the anonymous channel for encrypting their messages from the CP generator as off-line processes. Then, once encryption keys are shared between senders and servers, servers in the anonymous channel can efficiently transfer messages of senders to their receivers while exploiting symmetric key encryption functions.

According to experimentations, the capacity of ESEBM is more than 36 times higher than that of decryption type Mix net. Different from asymmetric key encryption functions, symmetric key encryption functions also enable message receivers to send reply messages to the anonymous senders in totally the same way as the senders send original messages, and consequently, anyone except the receivers cannot identify even whether messages are replies or not. Also, the CP generator configuration disables unauthorized entities to send messages because only authorized entities that had obtained secret keys from the CP generator can send messages. Therefore, ESEBM is secure against various kinds of attacks including DOS attacks and message forgeries (or modifications) that are difficult to prevent in existing anonymous networks.

\section{REQUIREMENTS FOR ANONYMOUS NETWORKS}

Anonymous networks should satisfy the following requirements, i.e.,

1. no one except senders of messages can know identities of the senders,

2. message senders can confirm their message arrivals at their receivers without disclosing their identities,

3. receivers can send reply messages back to the senders without knowing the senders' identities, 
4. anonymous networks must be able to protect themselves from accesses from unauthorized entities, and

5. anonymous networks must maintain their performances as same as usual ones.

The 1st requirement is the most important one, and senders of messages must be concealed not only from the receivers but also from network managers, eavesdroppers and any other entities. The 2 nd and the 3 rd requirements are also important, and especially the 3rd one is essential because information exchanges between entities in many kinds of applications are carried out as conversations between them. To satisfy the 2 nd requirement is not so difficult, e. g. senders can confirm deliveries of their messages without disclosing their identities when the receivers put receive signals in public bulletin boards. However, development of practical mechanisms that satisfy the 3rd requirement is not easy as it looks. For example, a receiver, which sends reply message $M_{\mathrm{R}}$, can identify the sender of the original message by eavesdropping on the communication channel to find out the entity that receives $M_{\mathrm{R}}$, because it knows $M_{R}$. About the 4th requirement, because of anonymity, entities can behave dishonestly much easier than in usual communication systems, therefore, anonymous communication mechanisms must be endowed with the ability to protect them from dishonest events. The important thing here is that dishonest events must be prevented while maintaining anonymities of honest entities. Finally, to use anonymous networks in large scale applications where large volumes of messages are exchanged frequently, they must be efficient enough as usual non-anonymous networks.

\section{RELATED WORKS}

This section summarizes currently available anonymous networks. Although many various kinds of anonymous networks had been proposed already, still they cannot satisfy the requirements in the previous section effectively. Mixnet is an example. It consists of a sequence of mixservers $\mathrm{T}_{1}, \mathrm{~T}_{2},---, \mathrm{T}_{\mathrm{N}}$, that relay messages from senders to their receivers. Where, senders send their messages while encrypting them repeatedly by public keys of multiple mixservers $\mathrm{T}_{1}, \mathrm{~T}_{2},---, \mathrm{T}_{\mathrm{N}}$ in the sequence. Then, individual mixservers relay their receiving messages to their neighboring servers while decrypting them by their secret decryption keys finally to be sent to their receivers. Namely, sender $\mathrm{S}$ encrypts its message $M$ to $\mathrm{E}\left(\mathrm{k}_{\mathrm{N}}, \mathrm{E}\left(\mathrm{k}_{\mathrm{N}-1},---, \mathrm{E}\left(\mathrm{k}_{1}, M\right)---\right)\right)$ and each $\mathrm{T}_{\mathrm{j}}$ that recieves $\mathrm{E}\left(\mathrm{k}_{\mathrm{j}}, \mathrm{E}\left(\mathrm{k}_{\mathrm{j}-1},---, \mathrm{E}\left(\mathrm{k}_{1}, M\right)---\right)\right)$ from $\mathrm{T}_{\mathrm{j}+1}$ decrypts it to $\mathrm{E}\left(\mathrm{k}_{\mathrm{j}-1},---, \mathrm{E}\left(\mathrm{k}_{1}, M\right)---\right)$ by its secret decryption key $\mathrm{k}_{\mathrm{j}}^{-1}$ to forward it to $\mathrm{T}_{\mathrm{j}-1}$, where $\mathrm{E}\left(\mathrm{k}_{\mathrm{j}}, M\right)$ is the encrypted form of $M$. In this message relaying process, each mixserver stores its incoming messages until pre-defined number of message arrivals, and shuffles decrypted messages before forwarding them to its neighbor. Therefore, each mixserver cannot identify the links between incoming and outgoing messages of other mixservers, and as a consequence, no one except the senders themselves can identify the senders of messages unless all mixservers conspire.

However, Mixnet uses asymmetric key encryption functions, such as RSA or ElGamal, and does not work efficiently in large scale systems where number of senders send large volume of messages. A lot of computation overheads are needed to encrypt and decrypt messages. Asymmetric key encryption functions also make Mixnet require additional mechanisms for sending reply messages to senders of the original messages, therefore, servers can know whether the messages are replies or not $[1,7]$. Although Mixnet can protect itself from traffic analysis and replay attacks that are discussed in Sec. VI. A, it cannot prevent DOS attacks or message forgeries (or modifications). Encryption keys are publicly disclosed and servers cannot identify spam or forged messages because they receive messages in their encrypted forms, therefore, anyone can send spam and forged messages.

Crowds [4] also consists of multiple relay servers as same as Mixnet, however, senders send their messages without encrypting them. Instead of encrypting messages, servers randomly decide whether to relay their receiving messages to their receivers or to the other servers in the network. Namely, when a server receives a message from a sender, it forwards it to other server with probability 1-p and with probability $\mathrm{p}$ it sends it to the receiver. Then, it becomes difficult for entities other than the sender to identify the sender, and because no encryption or decryption process is included, Crowds can transfer messages efficiently. However, apparently it cannot disable entities to identify senders by tracing messages from their receivers to their senders. Namely, Crowds cannot satisfy the most important requirement of anonymous networks.

Onion routing $[3,8]$ uses the same principle as Mixnet, i.e. messages travel from senders to receivers through sequences of servers (onion routers) while being encrypted by public keys of multiple onion routers. The difference from Mixnet is that senders in onion routing encrypt not only their messages but also their routes, i.e. servers in onion routing reroute their receiving messages in unpredictable ways. Therefore, onion routers need not wait for large number of messages to shuffle them and can reduce message travelling times. However, onion routing uses asymmetric key encryption functions and shares the same drawbacks with Mixnet. An additional problem of onion routing is that it is vulnerable to timing attacks, i.e. an adversary can embed messages to know the flow times of different paths. Then, while using these message flow times, entities can know senders of messages by observing message sending and receiving times of individual senders and receivers.

Other anonymous networks such as Tor [8], buses for anonymous message delivery [6], Peer to Peer anonymous mechanisms [12], etc. have the same drawbacks as Mixnet or Onion routing.

In DC-net [2], sender $S_{q}$ constitutes a group $\left\{S_{1}, S_{2},---\right.$, $\mathrm{S}_{\mathrm{Q}}$ \} that includes itself, and entities in the group generate their secret numbers $\left\{N_{1}, N_{2},---, N_{Q}\right\}$ so that the sum of 
them becomes 0 in advance. While using its generating secret number, $\mathrm{S}_{\mathrm{q}}$ encrypts its message $M$ to $M+\mathrm{N}_{\mathrm{q}}$ to send it to its receiver $R$. At the same time, each $S_{j}$ in the group also sends its secret number $\mathrm{N}_{\mathrm{j}}$ to $\mathrm{R}$. Therefore, $\mathrm{R}$ can extract $M$ from messages of $\left\{\mathrm{S}_{1}, \mathrm{~S}_{2},---, \mathrm{S}_{\mathrm{Q}}\right\}$, i.e. $\mathrm{N}_{1}$ $+\mathrm{N}_{2}+---+\left(M+\mathrm{N}_{\mathrm{q}}\right)+\mathrm{N}_{\mathrm{q}+1}+---+\mathrm{N}_{\mathrm{Q}}=M+0=M$. However, no one except $\mathrm{S}_{\mathrm{q}}$ can know the sender of $M$, because each $S_{j}$ does not know secret numbers of other senders.

As shown above, DC-net provides almost perfect anonymity, however it has fatal drawbacks about its performance, i.e. multiple senders must behave synchronously. Multiple senders must agree with each other about random numbers to encrypt messages, also only one sender can send a message at a time. Therefore, it is applicable only to small and closed networks. Here, it must be noted that each $S_{j}$ must change random secret number $\mathrm{N}_{\mathrm{j}}$ at every message sending. If every $\mathrm{S}_{\mathrm{j}}$ uses same random secret number for different messages sent from senders in the group, an entity $\mathrm{X}$ that eavesdrops on the communication can easily identify senders of the messages. Namely, when $S_{j}$ sends same number $N_{j}$ as its 1st and 2nd messages, $X$ can know that $S_{j}$ 's random secret number is $\mathrm{N}_{\mathrm{j}}$. Also, when $\mathrm{S}_{\mathrm{j}}$ sends $\left(M_{\mathrm{j}}+\mathrm{N}_{\mathrm{j}}\right)$ and $\mathrm{N}_{\mathrm{j}}$ as its 1 st and 2 nd messages, it is easy for $\mathrm{X}$ to extract $M_{\mathrm{j}}$ and to identify the sender.

To decrease computation volumes of encryptions and decryptions, SEBM [13] exploits symmetric key encryption functions. SEBM consists of 2 parts, the encryption part and the decryption part, and messages are forwarded to their receivers while being encrypted by servers in the encryption part and decrypted by servers in the decryption part. Here different from other anonymous networks, senders themselves are included as relay servers in both parts to enable the use of symmetric key encryption functions. Therefore, although SEBM can satisfactory reduce the computation overheads caused by asymmetric key encryptions, senders included in the encryption and decryption parts reduce the stability of the communication. For example, when senders, i.e. volunteer servers, stop operations, messages cannot be forwarded. As another drawback, because messages in SEBM must be encrypted and decrypted by servers both in the encryption and the decryption parts, their travelling times increase. Also, it cannot efficiently handle reply messages or prevent accesses from unauthorized entities either.

\section{ESEBM (ENHANCED SYMMETRIC KEY ENCRYPTION BASED MIXNET)}

This section proposes ESEBM, a scheme for anonymous networks that efficiently satisfies all the requirements listed in the previous section. ESEBM removes most drawbacks that exist in other anonymous networks, i.e. it can transfer messages without large overheads, it does not require any additional mechanism for forwarding reply messages, and it can protect itself from various attacks.

\section{A. ESEBM Configuration}

ESEBM can be considered as a kind of decryption type Mixnet, in which asymmetric key encryption functions are replaced by symmetric ones, where the encryption keys used for sending messages are distributed to senders in advance. At the same time, it is considered as SEBM in which volunteer servers are replaced by permanent ones in order to make the network stable enough [15].

As shown in Fig. 1, ESEBM consists of 2 parts, i.e. the anonymous channel and the concealing pattern generator (CP generator). The anonymous channel is configured as a sequence of $\mathrm{N}$ servers as same as Mixnet, and the $\mathrm{CP}$ generator consists of Z-groups, where the g-th group is configured by $\mathrm{N}_{\mathrm{g}}$ servers, and each server in the anonymous channel is corresponded to a single server in the CP generator and vice versa, therefore $\mathrm{N}=\mathrm{N}_{1}+\mathrm{N}_{2}+$ --- $+\mathrm{N}_{\mathrm{Z}}$. In the remainder, notation $\mathrm{T}_{\mathrm{g}}(\mathrm{k})$ that represents the $\mathrm{k}$-th server in the g-th group of the $\mathrm{CP}$ generator is used also for representing the $\mathrm{p}$-th server $\mathrm{T}_{\mathrm{p}}$ in the anonymous channel that corresponds to $\mathrm{T}_{\mathrm{g}}(\mathrm{k})$, and vice versa.

ESEBM adopts onetime pad as the base algorithm to encrypt and decrypt messages, and sender $\mathrm{S}$ of message $M_{S}$ requests servers in the $\mathrm{CP}$ generator to issue a bit string called concealing pattern (CP), a pad for encrypting $M_{S}$, in advance as an off-line process.

Provided that servers generate their h-th $\mathrm{CP}$ at the request of $S$, each server $T_{j}$ in the $C P$ generator generates its $h$-th $\mathrm{CP}$ constructor $\mathrm{x}_{\mathrm{j}}(\mathrm{h})$, and the $\mathrm{h}$-th concealing pattern $\mathrm{X}(\mathrm{h})$ is constructed as $\mathrm{XOR}$ of them, i.e. $\mathrm{X}(\mathrm{h})=$ $\mathrm{x}_{1}(\mathrm{~h}) \oplus \mathrm{x}_{2}(\mathrm{~h}) \oplus---\oplus \mathrm{x}_{\mathrm{N}}(\mathrm{h})$. Then, $\mathrm{S}$ sends $M_{S}$ to the first server $\mathrm{T}_{1}$ in the anonymous channel while encrypting it to $M_{S} \oplus \mathrm{X}(\mathrm{h})$. Therefore, the length of $\mathrm{CPs}$ and $\mathrm{CP}$ constructors are defined as $\mathrm{L}_{\mathrm{M}}$, which is the length of messages. When $\mathrm{S}$ sends a long message $M_{S}, M_{S}$ is divided into multiple frames of length $\mathrm{L}_{\mathrm{M}}$. Here, $\mathrm{S}$ uses different CPs for encrypting different messages including different frames of the same message. Also, although notations $\mathrm{X}(\mathrm{h})$ and $\mathrm{x}_{\mathrm{j}}(\mathrm{h})$ are accompanied by $\mathrm{h}$ they do not include any information about $\mathrm{h}$.

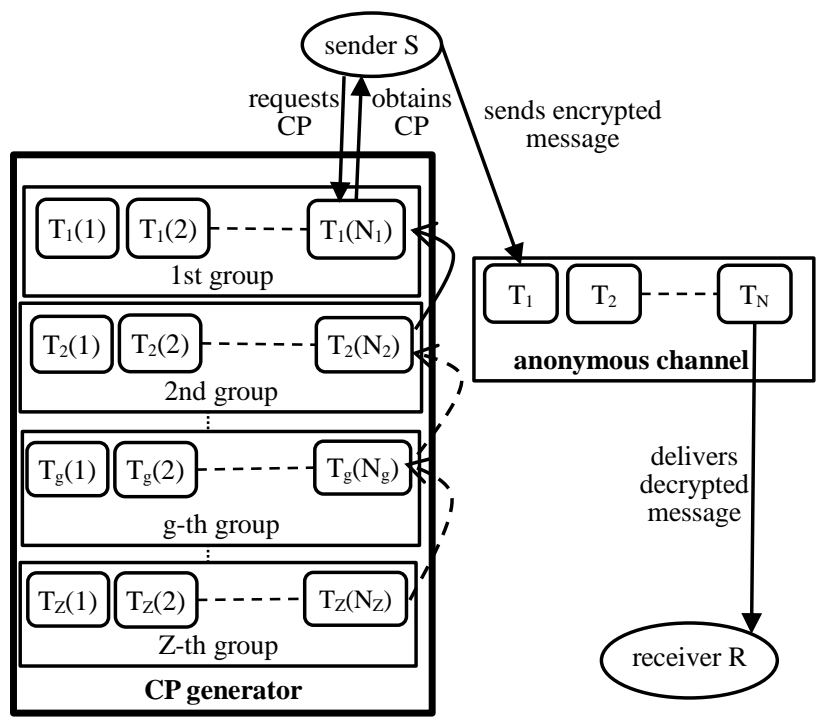

Figure 1. ESEBM configuration 


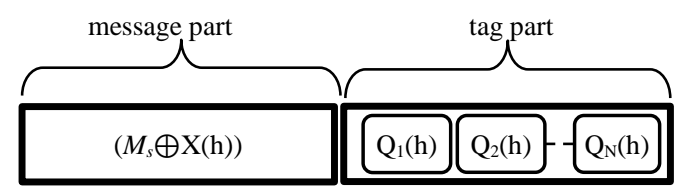

Figure 2. Message structure

As same as usual Mixnet, each server in the anonymous channel stores its receiving messages until it receives the predefined number of messages, and decrypts, shuffles and forwards them to its neighboring server finally to be sent to their receivers. Here, each $\mathrm{T}_{\mathrm{j}}$ decrypts its receiving encrypted $M_{S}$ by simply XORing it by its CP constructor $\mathrm{x}_{\mathrm{j}}(\mathrm{h})$ that constitutes $\mathrm{X}(\mathrm{h})$, the $\mathrm{CP}$ that $\mathrm{S}$ had used to encrypt $M_{S}$, then, it is apparent that $M_{S} \oplus \mathrm{X}(\mathrm{h})$ is transformed to $M_{S}$ when all servers decrypt it. On the other hand, because each server knows only its CP constructor $\mathrm{x}_{\mathrm{j}}(\mathrm{h})$ in $\mathrm{X}(\mathrm{h})$, no one can know the sender of $M_{S}$ unless all servers conspire with each other as same as in usual Mixnet.

However, different from usual Mixnet where all senders encrypt their messages by using the same single public encryption key of each mixserver, in ESEBM, senders encrypt different messages by using different CPs, Therefore to enable $\mathrm{T}_{\mathrm{j}}$ to identify its $\mathrm{CP}$ constructor $\mathrm{x}_{\mathrm{j}}(\mathrm{h})$ that constitutes $\mathrm{X}(\mathrm{h})$ for encrypting $M_{S}$, message $M_{S}$ consists of the message part and the tag part as shown in Fig. 2. The message part maintains encrypted message $M_{S}$, i.e. $M_{S} \oplus \mathrm{X}(\mathrm{h})$, and the tag part maintains a sequence of tags, i.e. vector $\mathrm{Q}(\mathrm{h})=\left\{\mathrm{Q}_{1}(\mathrm{~h}), \mathrm{Q}_{2}(\mathrm{~h}),---, \mathrm{Q}_{\mathrm{N}}(\mathrm{h})\right\}$, where server $T_{j}$ that had generated the $\mathrm{CP}$ constructor $\mathrm{x}_{\mathrm{j}}(\mathrm{h})$ to construct $X(h)$ can know $x_{j}(h)$ from $Q_{j}(h)$. Here, $Q_{j}(h)$ is constructed so that no one can trace the message by it and no one except $\mathrm{T}_{\mathrm{j}}$ can identify $\mathrm{x}_{\mathrm{j}}(\mathrm{h})$ from it.

\section{B. Behavior of the CP Generator}

To disable entities to trace messages forwarded through the anonymous channel, not only correspondences between the message parts of input and output messages of individual servers but also those between their tag parts must be concealed. To achieve this, the $\mathrm{CP}$ generator generates 2 kinds of secret encryption keys shared between senders and individual servers, the one is CPs and the other is tag vectors (TVs). The CP generator is a set of server groups, each of which consists of at least 3 servers that generate their secret $\mathrm{CP}$ constructors and TV constructors independently of others to construct CPs and TVs jointly with other servers. Here, senders communicate only with servers in the 1st group, i.e. with $\mathrm{T}_{1}(1), \mathrm{T}_{1}(2)$, ---, and $\mathrm{T}_{1}\left(\mathrm{~N}_{1}\right)$, to disable servers in the other groups to know the senders as shown in Fig. 1.

As discussed already, concealing pattern $\mathrm{X}(\mathrm{h})$ is calculated as XOR of CP constructor $\mathrm{x}_{\mathrm{j}}(\mathrm{h})(\mathrm{j}=1,2,---, \mathrm{N})$ generated by each server $T_{j}$, and disables anyone to trace the message parts of a message relayed by the servers. On the other hand, individual elements of N-dimensional tag vector $\mathrm{Q}(\mathrm{h})=\left\{\mathrm{Q}_{1}(\mathrm{~h}), \mathrm{Q}_{2}(\mathrm{~h}),---, \mathrm{Q}_{\mathrm{N}}(\mathrm{h})\right\}$ disable anyone to trace the tag part of a message relayed by the servers, and each $\mathrm{Q}_{\mathrm{i}}(\mathrm{h})$ is calculated as XOR of the i-th elements of each N-dimensional TV constructor $\mathrm{q}_{\mathrm{j}}(\mathrm{h})=\{0$, --- 0 , $\left.\mathrm{q}_{\mathrm{j}(\mathrm{j}+1)}(\mathrm{h}), \mathrm{q}_{\mathrm{j}(\mathrm{j}+2)}(\mathrm{h}),---, \mathrm{q}_{\mathrm{jN}}(\mathrm{h})\right\}$ generated by $\mathrm{T}_{\mathrm{j}}(\mathrm{j}=1,---$
$N)$. Here, each $q_{j k}(h)$ in vector $q_{j}(h)$ is a bit pattern of length $\mathrm{L}_{\mathrm{T}}$ as discussed later, 0 represents an all zero bit pattern of length $\mathrm{L}_{T}$, and a sequence of j-zero patterns precedes before the $(\mathrm{N}-\mathrm{j})$-secret bit patterns $\left\{\mathrm{q}_{\mathrm{j}(\mathrm{j}+1)}(\mathrm{h})\right.$, $\left.\mathrm{q}_{\mathrm{j}(\mathrm{j}+2)}(\mathrm{h}),---, \mathrm{q}_{\mathrm{jN}}(\mathrm{h})\right\}$. By XORing CP constructors and TV constructors of individual serves, concealing pattern $\mathrm{X}(\mathrm{h})$ and tag vector $\mathrm{Q}(\mathrm{h})$ are calculated as $\mathrm{X}(\mathrm{h})=$ $\mathrm{x}_{1}(\mathrm{~h}) \oplus \mathrm{x}_{2}(\mathrm{~h}) \oplus---\oplus \mathrm{x}_{\mathrm{N}}(\mathrm{h}) \quad$ and $\quad \mathrm{Q}(\mathrm{h})=\left\{0, \quad \mathrm{q}_{12}(\mathrm{~h})\right.$, $\left.\mathrm{q}_{13}(\mathrm{~h}) \oplus \mathrm{q}_{23}(\mathrm{~h}), \quad---\mathrm{q}_{1 \mathrm{~N}}(\mathrm{~h}) \oplus \mathrm{q}_{2 \mathrm{~N}}(\mathrm{~h}) \oplus---\oplus \mathrm{q}_{(\mathrm{N}-1) \mathrm{N}}(\mathrm{h})\right\}$. Here, the length of bit pattern $x_{j}(h)$ is equal to the message frame length $\mathrm{L}_{\mathrm{M}}$ as mentioned before, and the last server $\mathrm{T}_{\mathrm{N}}$ does not generate its TV constructor.

CPs and TVs above are generated as follows. Provided that $\mathrm{T}_{1}(\mathrm{k})$ in the $1 \mathrm{st}$ group of the $\mathrm{CP}$ generator corresponds to $\mathrm{T}_{\mathrm{k}^{*}}$ in the anonymous channel, i.e. $\mathrm{T}_{1}(1)=\mathrm{T}_{1^{*}}, \mathrm{~T}_{1}(2)=$ $\mathrm{T}_{2^{*},---}$, and $\mathrm{T}_{1}\left(\mathrm{~N}_{1}\right)=\mathrm{T}_{\mathrm{N} 1^{*}}$, firstly, sender $\mathrm{S}$ sends a set of its secret private vectors $(\mathrm{PVs})\left\{\mathrm{P}_{1}(\mathrm{~h}), \mathrm{P}_{2}(\mathrm{~h}),---, \mathrm{P}_{\mathrm{N} 1}(\mathrm{~h})\right\}$ as a request for a $\mathrm{CP}$ to servers $\mathrm{T}_{1^{*}}, \mathrm{~T}_{2^{*}},---, \mathrm{T}_{\mathrm{N} 1^{*}}$, respectively, as shown in Fig. 3 (a). Here, each $P_{j}(h)$ is vector $\left\{p_{j 0}(h), p_{j 1}(h),---p_{j N}(h)\right\}$ and except $p_{j 0}(h), p_{j k}(h)$ is a bit pattern of the same length as element $\mathrm{q}_{\mathrm{jk}}(\mathrm{h})$ in $\mathrm{TV}$ constructor $\mathrm{q}_{\mathrm{j}}(\mathrm{h})$. Bit pattern $\mathrm{p}_{\mathrm{j} 0}(\mathrm{~h})$ has the same length as CP constructor $\mathrm{x}_{\mathrm{j}}(\mathrm{h})$.

Then, $\mathrm{T}_{1^{*}}$ that receives the request with $\mathrm{P}_{1}(\mathrm{~h})$, generates its CP constructor $\mathrm{x}_{1 *}(\mathrm{~h})$ and TV constructor $\mathrm{q}_{1 *}(\mathrm{~h})=\{0$, ---, $\left.\quad 0, \quad \mathrm{q}_{1 *(1 *+1)}(\mathrm{h}), \quad \mathrm{q}_{1 *(1 *+2)}(\mathrm{h}), \quad---, \quad \mathrm{q}_{1 * \mathrm{~N}}(\mathrm{~h})\right\} . \quad$ It also generates $\mathrm{ID}_{1 *}\left(\mathrm{x}_{1 *}(\mathrm{~h}), \mathrm{q}_{1 *}(\mathrm{~h})\right)$ as an address of $\mathrm{CP}$ and $\mathrm{TV}$ constructor pair $\left(\mathrm{x}_{1 *}(\mathrm{~h}), \mathrm{q}_{1 *}(\mathrm{~h})\right)$. Here, $\mathrm{T}_{1 *}$ maintains its $\mathrm{CP}$ table, a list of $\mathrm{CP}$ and $\mathrm{TV}$ constructors that it had generated, and $\operatorname{ID}_{1 *}\left(\mathrm{x}_{1 *}(\mathrm{~h}), \mathrm{q}_{1 *}(\mathrm{~h})\right)$ represents the address of the constructor pair $\left\{\mathrm{x}_{1 *}(\mathrm{~h}), \mathrm{q}_{1 *}(\mathrm{~h})\right\}$ in the table. Also, the length of each bit pattern $\mathrm{q}_{\mathrm{jk}}(\mathrm{h})$ in TV constructor $\mathrm{q}_{\mathrm{j}}(\mathrm{h})$ is set as $\mathrm{L}_{\mathrm{T}}$, the length of $\operatorname{ID}_{\mathrm{j}}\left(\mathrm{x}_{\mathrm{j}}(\mathrm{h}), \mathrm{q}_{\mathrm{j}}(\mathrm{h})\right)$.

Then, $\mathrm{X}(1, \mathrm{~h})$ and $\mathrm{Q}(1, \mathrm{~h})$, the h-th $\mathrm{CP}$ and TV that the 1 st group generates, are constructed by 1 st server $\mathrm{T}_{1}{ }^{*}$ as $\mathrm{X}(1, \mathrm{~h})=\mathrm{p}_{10}(\mathrm{~h}) \oplus \mathrm{x}_{1 *}(\mathrm{~h})$ and $\mathrm{Q}(1, \mathrm{~h})=\left\{\mathrm{p}_{11}(\mathrm{~h}), \mathrm{p}_{12}(\mathrm{~h}),---\right.$, $\mathrm{p}_{11^{*}}(\mathrm{~h}) \oplus \mathrm{ID}_{1 *}\left(\mathrm{x}_{1 *}(\mathrm{~h}), \quad \mathrm{q}_{1 *}(\mathrm{~h})\right), \quad \mathrm{p}_{1\left(1^{*}+1\right)}(\mathrm{h}) \oplus \mathrm{q}_{1 *(1 *+1)}(\mathrm{h})$, $\left.\mathrm{p}_{1\left(1^{*}+2\right)}(\mathrm{h}) \oplus \mathrm{q}_{1^{*}\left(1^{*}+2\right)}(\mathrm{h}),---, \mathrm{p}_{1 \mathrm{~N}}(\mathrm{~h}) \oplus \mathrm{q}_{1^{*} \mathrm{~N}}(\mathrm{~h})\right\}$, respectively. $\mathrm{X}(1, \mathrm{~h})$ and $\mathrm{Q}(1, \mathrm{~h})$ are then forwarded to $\mathrm{T}_{2^{*}}$. However, to protect them from eavesdropping, they are encrypted by the secret key $\mathrm{k}_{1 *}$ that is shared between $\mathrm{T}_{1^{*}}$ and $\mathrm{T}_{2 *}$, i.e. $\mathrm{X}(1, \mathrm{~h})$ and $\mathrm{Q}(1, \mathrm{~h})$ are sent to $\mathrm{T}_{2^{*}}$ in the form $\mathrm{E}\left(\mathrm{k}_{1^{*}}\right.$, $\mathrm{X}(1, \mathrm{~h}), \mathrm{Q}(1, \mathrm{~h}))$, where, $\mathrm{E}\left(\mathrm{k}_{1^{*}}, \mathrm{x}\right)$ represents $\mathrm{x}$ encrypted by key $\mathrm{k}_{1^{*}}$. It is also possible that $\mathrm{T}_{1^{*}}$ encrypts $\mathrm{X}(1, \mathrm{~h})$ and $\mathrm{Q}(1, \mathrm{~h})$ by using a public key of $\mathrm{T}_{2 *}$, however to decrease encryption overheads, a symmetric key encryption function is adopted here.

$\mathrm{T}_{2^{*}}$ that receives $\mathrm{E}\left(\mathrm{k}_{1^{*}},\{\mathrm{X}(1, \mathrm{~h}), \mathrm{Q}(1, \mathrm{~h})\}\right)$ decrypts it to $\{\mathrm{X}(1, \mathrm{~h}), \mathrm{Q}(1, \mathrm{~h})\}$, and generates its $\mathrm{CP}$ constructor $\mathrm{x}_{2 *}(\mathrm{~h})$ to modify $\mathrm{X}(1, \mathrm{~h})$ to $\mathrm{X}(1, \mathrm{~h})=$ $\mathrm{p}_{10}(\mathrm{~h}) \oplus \mathrm{p}_{20}(\mathrm{~h}) \oplus \mathrm{x}_{1 *}(\mathrm{~h}) \oplus \mathrm{x}_{2 *}(\mathrm{~h}) . \quad \mathrm{T}_{2^{*}} \quad$ also generates $\mathrm{TV}$ constructor $\mathrm{q}_{2 *}(\mathrm{~h})=\left(0,---0, \mathrm{q}_{2 *(2 *+1)}(\mathrm{h}), \mathrm{q}_{2 *(2 *+2)}(\mathrm{h}),---\right.$, $\left.\mathrm{q}_{2 * \mathrm{~N}}(\mathrm{~h})\right)$ to modify $\mathrm{Q}(1, \mathrm{~h})$ to $\left\{\mathrm{p}_{11}(\mathrm{~h}) \oplus \mathrm{p}_{21}(\mathrm{~h})\right.$, $\mathrm{p}_{12}(\mathrm{~h}) \oplus \mathrm{p}_{22}(\mathrm{~h}), \quad---, \quad \mathrm{p}_{11 *}(\mathrm{~h}) \oplus \mathrm{p}_{21 *}(\mathrm{~h}) \oplus \mathrm{ID}_{1^{*}}\left(\mathrm{x}_{1 *}(\mathrm{~h}), \quad \mathrm{q}_{1 *}(\mathrm{~h})\right)$, $\mathrm{p}_{1\left(1^{*}+1\right)}(\mathrm{h}) \oplus \mathrm{p}_{2\left(1^{*}+1\right)}(\mathrm{h}) \oplus \mathrm{q}_{1^{*}\left(1^{*}+1\right)}(\mathrm{h}), \quad---, \quad \mathrm{p}_{12^{*}}(\mathrm{~h}) \oplus \mathrm{p}_{22^{*}}(\mathrm{~h})$ $\oplus \mathrm{q}_{1 * 2 *}(\mathrm{~h}) \oplus \mathrm{ID}_{2 *}\left(\mathrm{x}_{2 *}(\mathrm{~h}), \quad \mathrm{q}_{2 *}(\mathrm{~h})\right), \quad \mathrm{p}_{1\left(2^{*}+1\right)}(\mathrm{h}) \oplus \mathrm{p}_{2\left(2^{*}+1\right)}(\mathrm{h})$ $\oplus \mathrm{q}_{1 *(2 *+1)}(\mathrm{h}) \oplus \mathrm{q}_{2 *(2 *+1)}(\mathrm{h}), \quad---, \mathrm{p}_{1 \mathrm{~N}}(\mathrm{~h}) \oplus \mathrm{p}_{2 \mathrm{~N}}(\mathrm{~h}) \oplus \mathrm{q}_{1 * \mathrm{~N}}(\mathrm{~h}) \oplus$ $\left.\mathrm{q}_{2 * \mathrm{~N}}(\mathrm{~h})\right\}$.

Here as same as $\mathrm{T}_{1^{*}}, \mathrm{~T}_{2^{*}}$ also maintains its $\mathrm{CP}$ table, and $\mathrm{ID}_{2 *}\left(\mathrm{x}_{2 *}(\mathrm{~h}), \mathrm{q}_{2 *}(\mathrm{~h})\right)$ represents the address where 
$\left\{\mathrm{x}_{2 *}(\mathrm{~h}), \mathrm{q}_{2 *}(\mathrm{~h})\right\}$ is located in it. Also, it is not necessary but to simplify the descriptions, it is assumed that servers in the anonymous channel are arranged so that $T_{j}(g)$ is placed at the earlier position in the anonymous channel than $T_{j}(h)$ when $g<h$, for every $j$-th group. Then, $X(1, h)$ and $\mathrm{Q}(1, \mathrm{~h})$ are sent to $\mathrm{T}_{3 *}$ while being encrypted by $\mathrm{k}_{2 *}$, a secret encryption key shared between $\mathrm{T}_{2^{*}}$ and $\mathrm{T}_{3^{*}}$, and this process continues until $\mathrm{T}_{\mathrm{N} 1 *}$ calculates $\mathrm{X}(1, \mathrm{~h})$ and $\mathrm{Q}(1$, $\mathrm{h})$. Therefore, $\mathrm{X}(1, \mathrm{~h})$ and $\mathrm{Q}(1, \mathrm{~h})=\left\{\mathrm{Q}_{1}(1, \mathrm{~h}), \mathrm{Q}_{2}(1, \mathrm{~h})\right.$, ---, $\left.\mathrm{Q}_{\mathrm{N}}(1, \mathrm{~h})\right\}$, the $\mathrm{CP}$ and the TV pair generated by the 1 st group becomes as shown in equations (1) - (3).

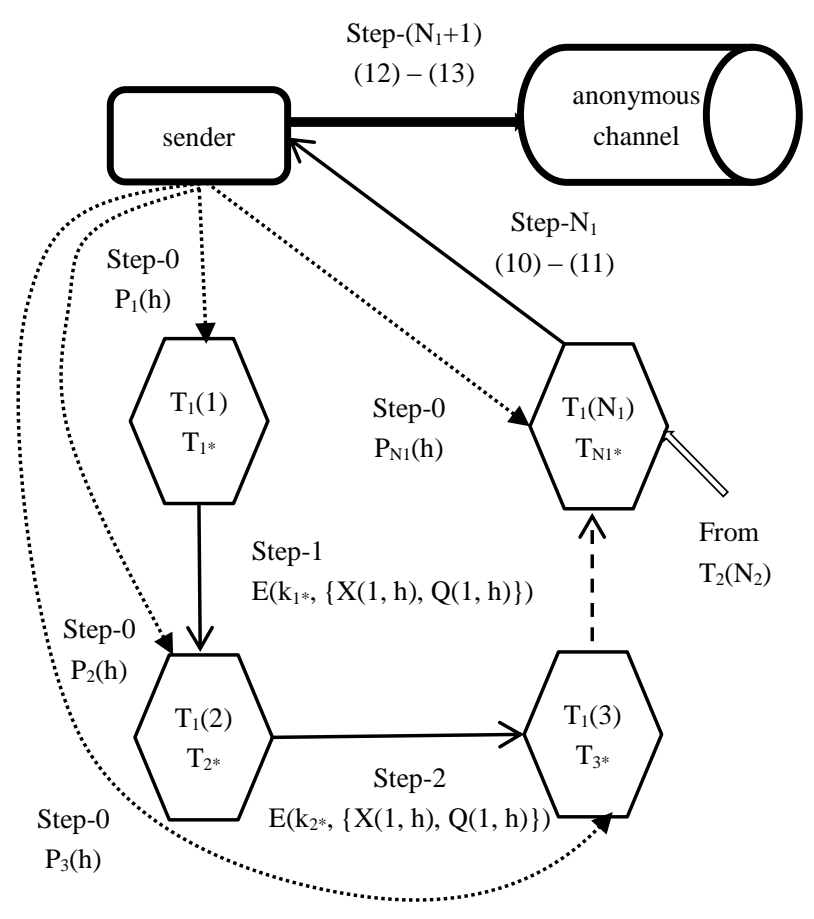

(a) 1 st group

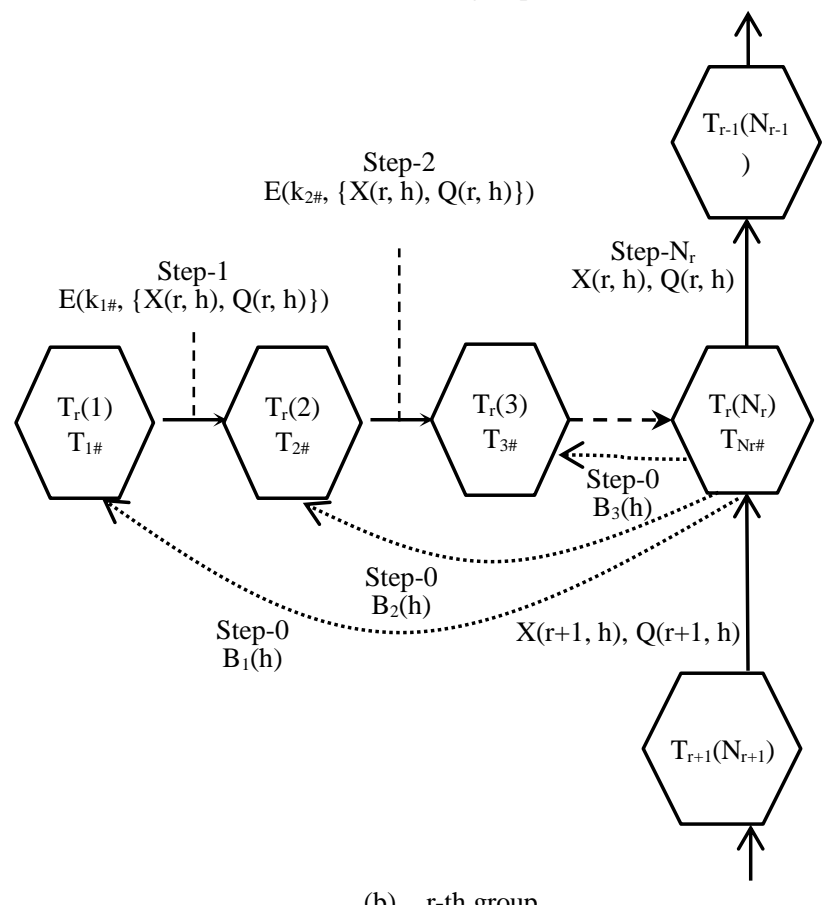

Figure 3. Behaviour of the $\mathrm{CP}$ generator

$$
\begin{aligned}
& \mathrm{X}(1, \mathrm{~h})=\mathrm{p}_{10} \oplus \mathrm{p}_{20} \oplus---\oplus \mathrm{p}_{(\mathrm{N} 1) 0} \oplus \mathrm{x}_{1 *}(\mathrm{~h}) \\
& \oplus \mathrm{x}_{2 *}(\mathrm{~h}) \oplus---\oplus \mathrm{x}_{(\mathrm{N} 1)^{*}}(\mathrm{~h})
\end{aligned}
$$

for $\mathrm{g}^{*}$ included in the 1st group $\mathrm{Q}_{\mathrm{g}^{*}}(1, \mathrm{~h})=\mathrm{p}_{1 \mathrm{~g}^{*}}(\mathrm{~h}) \oplus \mathrm{p}_{2 \mathrm{~g}^{*}}(\mathrm{~h}) \oplus---\oplus \mathrm{p}_{(\mathrm{N} 1) \mathrm{g}^{*}}(\mathrm{~h}) \oplus$ $\mathrm{q}_{1 * \mathrm{~g} *}(\mathrm{~h}) \oplus \mathrm{q}_{2 * \mathrm{~g} *}(\mathrm{~h}) \oplus---\oplus \mathrm{q}_{(\mathrm{g}-1) * \mathrm{~g}^{*}}(\mathrm{~h}) \oplus$

$\operatorname{ID}_{\mathrm{g} *}\left(\mathrm{X}_{\mathrm{g} *}(\mathrm{~h}), \mathrm{q}_{\mathrm{g} *}(\mathrm{~h})\right)$, where $\mathrm{q}_{0 * \mathrm{~g} *}(\mathrm{~h})=0$

for $i$ not included in the 1st group,

$\mathrm{Q}_{\mathrm{i}}(1, \mathrm{~h})=\mathrm{p}_{1 \mathrm{i}}(\mathrm{h}) \oplus \mathrm{p}_{2 \mathrm{i}}(\mathrm{h}) \oplus---\oplus \mathrm{p}_{(\mathrm{N} 1) \mathrm{i}}(\mathrm{h}) \oplus \mathrm{q}_{1 *_{\mathrm{i}}}(\mathrm{h})$

$\oplus \mathrm{q}_{2 * \mathrm{i}}(\mathrm{h}) \oplus---\oplus \mathrm{q}_{(\mathrm{g} ;)_{\mathrm{i}}}(\mathrm{h})$, where $\mathrm{g}_{\mathrm{j} *}<\mathrm{i}<\mathrm{g}_{(\mathrm{j}+1)^{*}}$

Severs in the $r$-th group $(r>1)$ behave in the same way as the 1st group as shown in Fig. 3 (b), where server $T_{r}(k)$,

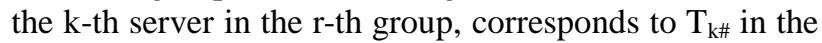
anonymous channel. However, different from the 1 st group where senders generate PVs and sends them as a request for a $\mathrm{CP}$ to severs $\mathrm{T}_{1^{*}}, \mathrm{~T}_{2^{*}},---, \mathrm{T}_{\mathrm{N} 1^{*}}$, servers $\mathrm{T}_{1 \# \text {, }}$, $\mathrm{T}_{2 \#,}$,---, $\mathrm{T}_{\mathrm{Nr}}$ in the $\mathrm{r}$-th group generate $\mathrm{CP}$ and $\mathrm{TV}$ pairs spontaneously without requests from senders, also the last server $\mathrm{T}_{\mathrm{N}_{\mathrm{r}} \#}$ in the $\mathrm{r}$-th group generates group blinding vector $B(h)=\left\{B_{1}(h), B_{2}(h),---, B_{N r}(h)\right\}$. Then, the $r-t h$ group calculates $X(r, h)$ and $Q(r, h)=\left\{Q_{1}(r, h), Q_{2}(r, h)\right.$, ---, $\left.\mathrm{Q}_{\mathrm{N}}(\mathrm{r}, \mathrm{h})\right\}$ as its h-th $\mathrm{CP}$ and TV values as shown in equations (4) - (6). In the equations, the $\mathrm{j}$-th element $B_{j}(h)$ of $B(h)=\left\{B_{1}(h), B_{2}(h),---, B_{N r}(h)\right\}$ is a vector of patterns $\left\{b_{j 0}(h), b_{j 1}(h),---, b_{j N}(h)\right\}$, where the length of $b_{j 0}(h)$ is $L_{M}$ and the length of $b_{j k}(h)$ is $L_{T}$ for each $k$.

$$
\begin{aligned}
& \mathrm{X}(\mathrm{r}, \mathrm{h})=\mathrm{b}_{10} \oplus \mathrm{b}_{20} \oplus---\oplus \mathrm{b}_{(\mathrm{Nr}) 0} \oplus \mathrm{x}_{1 \#}(\mathrm{~h}) \oplus \mathrm{x}_{2 \#}(\mathrm{~h}) \oplus \\
& ---\mathrm{x}_{\mathrm{Nr} \#}(\mathrm{~h})
\end{aligned}
$$

for $\mathrm{g \#}$ included in the r-th group

$$
\begin{aligned}
& \mathrm{Q}_{\mathrm{g} \#}(\mathrm{r}, \mathrm{h})=\mathrm{b}_{1 \mathrm{~g} \#}(\mathrm{~h}) \oplus \mathrm{b}_{2 \mathrm{~g} \#}(\mathrm{~h}) \oplus---\mathrm{b}_{(\mathrm{Nr}) \mathrm{g} \#}(\mathrm{~h}) \oplus \mathrm{q}_{1 \# \mathrm{~g} \#}(\mathrm{~h}) \oplus \\
& \mathrm{q}_{2 \# \mathrm{~g} \#}(\mathrm{~h}) \oplus---\oplus \mathrm{q}_{(\mathrm{g}-1) \# \mathrm{~g} \#}(\mathrm{~h}) \oplus \mathrm{ID}_{\mathrm{g} \#}\left(\mathrm{x}_{\mathrm{g} \#}(\mathrm{~h}), \mathrm{q}_{\mathrm{g} \#}(\mathrm{~h})\right), \\
& \text { where } \mathrm{q}_{\mathrm{g} \# \mathrm{~g} \#}(\mathrm{~h})=0
\end{aligned}
$$

for $i$ not included in the r-th group, $\mathrm{Q}_{\mathrm{i}}(\mathrm{r}, \mathrm{h})=\mathrm{b}_{1 \mathrm{i}}(\mathrm{h}) \oplus \mathrm{b}_{2 \mathrm{i}}(\mathrm{h}) \oplus---\oplus \mathrm{b}_{(\mathrm{Nr}) \mathrm{i}}(\mathrm{h}) \oplus \mathrm{q}_{1 \# \mathrm{i}}(\mathrm{h}) \oplus$ $\mathrm{q}_{2 \# i_{i}}(\mathrm{~h}) \oplus----\oplus \mathrm{q}_{(\mathrm{gjH}) \mathrm{i}}(\mathrm{h})$, where $\mathrm{g}_{\mathrm{j} \#}<\mathrm{i}<\mathrm{g}_{(\mathrm{j}+1) \#}$

After calculating $\mathrm{X}(\mathrm{r}, \mathrm{h})$ and $\mathrm{Q}(\mathrm{r}, \mathrm{h})$ as equations (4) (6), $\mathrm{T}_{\mathrm{Nr} \#}$ removes group blinding vector $\mathrm{B}(\mathrm{h})$ by XORing them by $\mathrm{B}(\mathrm{h})$. Namely, they are transformed as shown in equations (7) - (9).

$$
\begin{aligned}
& \mathrm{X}(\mathrm{r}, \mathrm{h})=\mathrm{x}_{1 \#}(\mathrm{~h}) \oplus \mathrm{x}_{2 \#}(\mathrm{~h}) \oplus----\oplus \mathrm{x}_{\mathrm{Nr} \#}(\mathrm{~h}) \\
& \text { for g\# included in the r-th group } \\
& \mathrm{Q}_{\mathrm{g} \#}(\mathrm{r}, \mathrm{h})=\mathrm{q}_{1 \# \mathrm{~g} \#}(\mathrm{~h}) \oplus \mathrm{q}_{2 \# \mathrm{~g} \#}(\mathrm{~h}) \oplus---\mathrm{q}_{(\mathrm{g}-1) \# \mathrm{~g} \#}(\mathrm{~h}) \oplus \\
& \mathrm{ID}_{\mathrm{g} \#}\left(\mathrm{x}_{\mathrm{g} \#}(\mathrm{~h}), \mathrm{q}_{\mathrm{g} \#}(\mathrm{~h})\right) \text {, where } \mathrm{q}_{\mathrm{o} \# \mathrm{~g} \#}(\mathrm{~h})=0
\end{aligned}
$$

for $i$ not included in the r-th group,

$\mathrm{Q}_{\mathrm{i}}(\mathrm{r}, \mathrm{h})=\mathrm{q}_{1+\mathrm{ti}}(\mathrm{h}) \oplus \mathrm{q}_{2 \# \mathrm{i}}(\mathrm{h}) \oplus---\oplus \mathrm{q}_{(\mathrm{gj} \#) \mathrm{i}}(\mathrm{h})$,

where $\mathrm{g}_{\mathrm{j} \#}<\mathrm{i}<\mathrm{g}_{(\mathrm{j}+1) \#}$

The last server $\mathrm{T}_{\mathrm{r}}\left(\mathrm{N}_{\mathrm{r}}\right)=\mathrm{T}_{\mathrm{Nr}}$ in the $\mathrm{r}$-th group also receives $\mathrm{X}(\mathrm{r}+1, \mathrm{~h})$ and $\mathrm{Q}(\mathrm{r}+1, \mathrm{~h})$, the $\mathrm{CP}$ and $\mathrm{TV}$ values generated by the $(r+1)$-th group, from $T_{r+1}\left(N_{r+1}\right)$, the last server in the $(r+1)$-th group, and it calculates $X(r$, $\mathrm{h}) \oplus \mathrm{X}(\mathrm{r}+1, \mathrm{~h})$, and $\mathrm{Q}(\mathrm{r}, \mathrm{h}) \oplus \mathrm{Q}(\mathrm{r}+1, \mathrm{~h})$ to combine CPs and 
TVs generated by the $\mathrm{r}$-th and the $(\mathrm{r}+1)$-th groups into the single $C P$ and $T V$, respectively. Then, $T_{r}\left(N_{r}\right)$ waits for the arrivals of predefined number of $\mathrm{CP}$ and $\mathrm{TV}$ pairs, and shuffles them to sends the results to the last server $\mathrm{T}_{\mathrm{r}-1}\left(\mathrm{~N}_{\mathrm{r}-1}\right)$ of the (r-1)-th group. As the result of the behaviors of all groups, the last server of the 1st group, i.e. $\mathrm{T}_{1}\left(\mathrm{~N}_{1}\right)$, generates the $\mathrm{CP}$ and $\mathrm{TV}$ as equations (10) and (11).

$$
\begin{aligned}
& \mathrm{X}(\mathrm{h})=\mathrm{p}_{10}(\mathrm{~h}) \oplus \mathrm{p}_{20}(\mathrm{~h}) \oplus---\oplus \mathrm{p}_{(\mathrm{N} 1) 0}(\mathrm{~h}) \oplus \mathrm{x}_{1}(\mathrm{~h}) \oplus \\
& \mathrm{x}_{2}(\mathrm{~h}) \oplus---\mathrm{x}_{\mathrm{N}}(\mathrm{h}) \\
& \mathrm{Q}_{\mathrm{g}}(\mathrm{h})=\mathrm{p}_{1 \mathrm{~g}}(\mathrm{~h}) \oplus---\mathrm{p}_{(\mathrm{N} 1) \mathrm{g}}(\mathrm{h}) \oplus \mathrm{q}_{1 \mathrm{~g}}(\mathrm{~h}) \oplus---\oplus \\
& \mathrm{q}_{(\mathrm{g}-1) \mathrm{g}}(\mathrm{h}) \oplus \mathrm{ID}_{\mathrm{g}}\left(\mathrm{x}_{\mathrm{g}}(\mathrm{h}), \mathrm{q}_{\mathrm{g}}(\mathrm{h})\right), \text { where } \mathrm{q}_{\mathrm{gg}}(\mathrm{h})=0
\end{aligned}
$$

Then, $\mathrm{T}_{1}\left(\mathrm{~N}_{1}\right)$ sends $\mathrm{X}(\mathrm{h})$ and $\mathrm{Q}(\mathrm{h})=\left\{\mathrm{Q}_{1}(\mathrm{~h}), \mathrm{Q}_{2}(\mathrm{~h}),---\right.$, $\left.\mathrm{Q}_{\mathrm{N}}(\mathrm{h})\right\}$ to sender $\mathrm{S}$, and $\mathrm{S}$ removes private vectors PVs from $\mathrm{X}(\mathrm{h})$ and $\mathrm{Q}(\mathrm{h})$ by XORing them by PVs. As the result, finally $\mathrm{CP}$ and TV values become as (12) and (13).

$$
\begin{aligned}
& X(h)=x_{1}(h) \oplus x_{2}(h) \oplus---\oplus x_{(N-1)}(h) \oplus x_{N}(h) \\
& Q_{g}(h)=q_{1 g}(h) \oplus---\oplus q_{(g-1) g}(h) \oplus I D_{g}\left(x_{g}(h), q_{g}(h)\right), \\
& \text { where } q_{0 g}(h)=0
\end{aligned}
$$

It must be noted that because PVs and group blinding vectors are secrets of sender $\mathrm{S}$ and last server of each group (except the 1st group), respectively, and each server $T_{j}$ does not disclose $x_{j}(h)$ or $q_{j}(h)$ to others, any server cannot know CP or TV constructors of other servers. No server can know $\mathrm{X}(\mathrm{h})$ or $\mathrm{Q}(\mathrm{h})$ either unless all servers conspire with each other.

\section{Behavior of the Anonymous Channel}

Fig. 4 shows the behavior of the anonymous channel. Firstly, sender $S$ encrypts its message $M_{S}$ by XORing it by concealing pattern $\mathrm{X}(\mathrm{h})$ that it had acquired from $\mathrm{T}_{1}\left(\mathrm{~N}_{1}\right)$. S also attaches tag vector $\mathrm{Q}(\mathrm{h})=\left\{\mathrm{Q}_{1}(\mathrm{~h}), \mathrm{Q}_{2}(\mathrm{~h})\right.$, ---, $\left.\mathrm{Q}_{\mathrm{N}}(\mathrm{h})\right\}$ corresponding to $\mathrm{X}(\mathrm{h})$, to the message, and sends $\left\{\underline{M}_{S}=\mathrm{x}_{1}(\mathrm{~h}) \oplus \mathrm{x}_{2}(\mathrm{~h}) \oplus---\oplus \mathrm{x}_{\mathrm{N}}(\mathrm{h}) \oplus M_{S}, \mathrm{Q}_{1}(\mathrm{~h}), \mathrm{Q}_{2}(\mathrm{~h})\right.$, ---, $\left.\mathrm{Q}_{\mathrm{N}}(\mathrm{h})\right\}$ to the 1 st server $\mathrm{T}_{1}$ in the anonymous channel. Here, $\mathrm{Q}_{1}(\mathrm{~h})$ has the form $\operatorname{ID}_{1}\left(\mathrm{x}_{1}(\mathrm{~h}), \mathrm{q}_{1}(\mathrm{~h})\right)$.

Then, $\mathrm{T}_{1}$ that receives $\left\{\mathrm{x}_{1}(\mathrm{~h}) \oplus \mathrm{x}_{2}(\mathrm{~h}) \oplus---\oplus \mathrm{x}_{\mathrm{N}}(\mathrm{h}) \oplus M_{S}\right.$, $\left.\mathrm{Q}_{1}(\mathrm{~h}), \mathrm{Q}_{2}(\mathrm{~h}),---, \mathrm{Q}_{\mathrm{N}}(\mathrm{h})\right\}$ retrieves $\mathrm{CP}$ constructor $\mathrm{x}_{1}(\mathrm{~h})$ and TV constructor $\mathrm{q}_{1}(\mathrm{~h})$ from its $\mathrm{CP}$ table based on $\mathrm{ID}_{1}\left(\mathrm{x}_{1}(\mathrm{~h}), \mathrm{q}_{1}(\mathrm{~h})\right)$ in $\mathrm{Q}_{1}(\mathrm{~h})$, calculates XOR of $\mathrm{x}_{1}(\mathrm{~h})$ and $\underline{M}_{S}$, and $\mathrm{q}_{1 \mathrm{j}}(\mathrm{h})$ and $\mathrm{Q}_{\mathrm{j}}(\mathrm{h})$ for each $\mathrm{j}$ as new values of $\underline{M}_{S}$ and $\mathrm{Q}_{\mathrm{j}}(\mathrm{h})$. Therefore, $\underline{M}_{S}$ and $\mathrm{Q}_{\mathrm{j}}(\mathrm{h})$ become $\underline{M}_{S}=$ $\mathrm{x}_{1}(\mathrm{~h}) \oplus\left(\mathrm{x}_{1}(\mathrm{~h}) \oplus \mathrm{x}_{2}(\mathrm{~h}) \oplus---\oplus \mathrm{x}_{\mathrm{N}}(\mathrm{h}) \oplus M_{S}\right)$

$\mathrm{x}_{2}(\mathrm{~h}) \oplus \mathrm{x}_{3}(\mathrm{~h}) \oplus---\oplus \mathrm{x}_{\mathrm{N}}(\mathrm{h}) \oplus M_{S} \quad$ and $\quad \mathrm{Q}_{\mathrm{j}}(\mathrm{h}) \quad=$ $\mathrm{q}_{1 \mathrm{j}}(\mathrm{h}) \oplus\left(\mathrm{q}_{1 \mathrm{j}}(\mathrm{h}) \oplus \mathrm{q}_{2 \mathrm{j}}(\mathrm{h}) \oplus---\oplus \mathrm{q}_{\mathrm{j}-1) \mathrm{j}}(\mathrm{h}) \oplus \mathrm{ID} \mathrm{D}_{\mathrm{j}}\left(\mathrm{x}_{\mathrm{j}}(\mathrm{h}), \quad \mathrm{q}_{\mathrm{j}}(\mathrm{h})\right)\right)=$ $\mathrm{q}_{2 \mathrm{j}}(\mathrm{h}) \oplus \mathrm{q}_{3 \mathrm{j}}(\mathrm{h}) \oplus---\oplus \mathrm{q}_{\mathrm{j}-1) \mathrm{j}}(\mathrm{h}) \oplus I \mathrm{D}_{\mathrm{j}}\left(\mathrm{x}_{\mathrm{j}}(\mathrm{h}), \mathrm{q}_{\mathrm{j}}(\mathrm{h})\right)$. After that, $\mathrm{T}_{1}$ removes $\mathrm{Q}_{1}(\mathrm{~h})$ from the tag part, waits for the predefined number of message arrivals, and shuffles them to forward each result to server $\mathrm{T}_{2}$.

All servers in the anonymous channel perform in the same way, i.e. each $\mathrm{T}_{\mathrm{j}}$ converts its incoming message to $\left\{M_{S}=\mathrm{x}_{\mathrm{j}+1}(\mathrm{~h}) \oplus \mathrm{x}_{\mathrm{j}+2}(\mathrm{~h}) \oplus---\oplus \mathrm{x}_{\mathrm{N}}(\mathrm{h}) \oplus M_{S}, \mathrm{Q}_{\mathrm{j}+1}(\mathrm{~h}), \mathrm{Q}_{\mathrm{j}+2}(\mathrm{~h}),---\right.$ $\left.\mathrm{Q}_{\mathrm{N}}(\mathrm{h})\right\}$, where $\mathrm{Q}_{\mathrm{g}}(\mathrm{h})=\mathrm{q}_{(\mathrm{j}+1) \mathrm{g}}(\mathrm{h}) \oplus---\oplus \mathrm{q}_{(\mathrm{g}-1) \mathrm{g}}(\mathrm{h}) \oplus \mathrm{ID}_{\mathrm{g}}\left(\mathrm{x}_{\mathrm{g}}(\mathrm{h})\right.$, $\mathrm{q}_{\mathrm{g}}(\mathrm{h})$ ). Consequently, when $\mathrm{T}_{\mathrm{N}}$, the last server in the anonymous channel, completes its operations on the message, the message is converted into $M_{S}$, and $\mathrm{T}_{\mathrm{N}}$ can deliver $M_{S}$ to its receiver while extracting the address of the receiver from $M_{S}$.

The anonymous channel together with the $\mathrm{CP}$ generator protects identities of message senders from various threats as follows. Firstly, each server $T_{j}$ transforms the message part while XORing it by $\mathrm{CP}$ constructor $\mathrm{x}_{\mathrm{j}}(\mathrm{h})$ which is not known to other servers and also $\mathrm{T}_{\mathrm{j}}$ assigns different values as $\mathrm{CP}$ constructors for encrypting different messages. Therefore no one including other server $T_{i}$ can identify the input and output pair of $\mathrm{T}_{\mathrm{j}}$ that corresponding to $M_{S}$ by comparing message parts of $\mathrm{T}_{\mathrm{j}}$ 's receiving and forwarding messages. For $\mathrm{T}_{\mathrm{i}}, 2$ input and output pairs of $\mathrm{T}_{\mathrm{j}}$, e. $\mathrm{g}$. $\left\{\mathrm{x}_{\mathrm{j}}(\mathrm{h}) \oplus \mathrm{x}_{\mathrm{j}+1}(\mathrm{~h}) \oplus---\oplus \mathrm{x}_{\mathrm{N}}(\mathrm{h}) \oplus M_{S}, \quad \mathrm{x}_{\mathrm{j}+1}\left(\mathrm{~h}_{1}\right) \oplus---\oplus \mathrm{x}_{\mathrm{N}}\left(\mathrm{h}_{1}\right) \oplus M_{l}\right\}$ and $\left\{\mathrm{x}_{\mathrm{j}}(\mathrm{h}) \oplus \mathrm{x}_{\mathrm{j}+1}(\mathrm{~h}) \oplus---\oplus \mathrm{x}_{\mathrm{N}}(\mathrm{h}) \oplus M_{S}, \quad \mathrm{x}_{\mathrm{j}+1}\left(\mathrm{~h}_{2}\right) \oplus---\oplus \mathrm{x}_{\mathrm{N}}\left(\mathrm{h}_{2}\right)\right.$ $\left.\oplus M_{2}\right\}$, have equal possibilities that they are encrypted form pairs of $M_{S}$. As a consequence, it is impossible for entities including servers to identify the sender of message $M_{S}$ by tracing the message parts of messages unless all servers conspire.

Any entity cannot trace $M_{S}$ by examining the tag parts of messages either. Because each $\mathrm{T}_{\mathrm{j}}$ generates different secret TV constructors for different messages and assigns different bit patterns to individual elements $\left\{\mathrm{q}_{\mathrm{j}(\mathrm{j}+1)}(\mathrm{h}),---\right.$, $\left.\mathrm{q}_{\mathrm{jN}}(\mathrm{h})\right\}$ in TV constructor $\mathrm{q}_{\mathrm{j}}(\mathrm{h})$, it is impossible for other entities to identify links between incoming messages of $T_{j}$ and its outgoing messages by examining pattern transitions in individual tags made by $T_{j}$. Namely, individual tags change their forms within $T_{j}$ in different ways, and entities except $T_{j}$ cannot extract any relation between transitions of different tags in the tag part to identify input and output pairs of same messages.

Also, although, each server $\mathrm{T}_{\mathrm{j}^{*}}$ in the 1 st group in the $\mathrm{CP}$ generator can know the senders of encrypted messages from their CP and TV constructors, because $T_{j^{*}}$ generates them at requests of the senders, when $T_{j^{*}}$ is placed at the earlier position of the anonymous channel, its tags disappear in the later positions, i.e. the tag parts of messages that are received by servers at later positions of the anonymous channel do not include tags of any server in the 1st group, therefore even if $T_{j^{*}}$ conspires with servers at the later positions, it is not possible to identify senders.

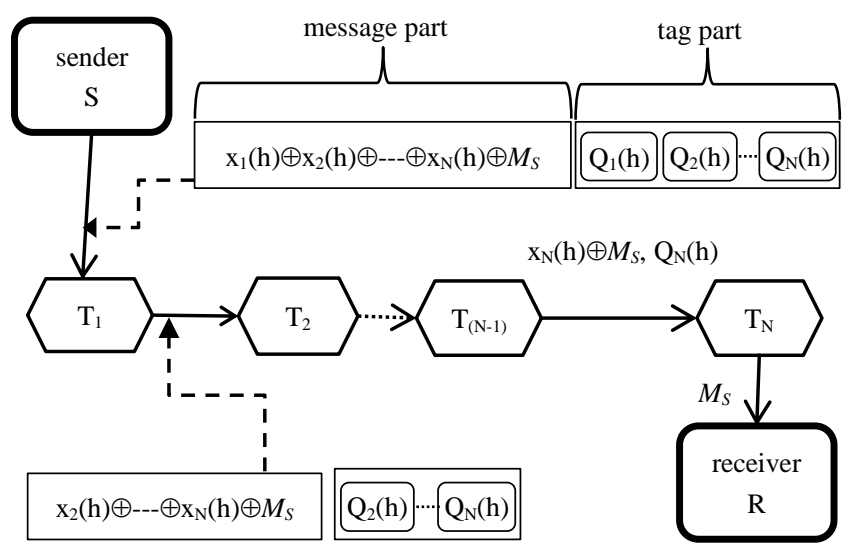

Figure 4. Behavior of the anonymous channel 


\section{REPLIES TO ANONYMOUS SENDERS}

Different from other existing mechanisms [2, 7], in ESEBM, individual servers can handle reply messages to anonymous senders without any additional mechanism. This means that servers cannot decide even whether a message is the reply or not. Sender $S$ can receive reply messages as follows. Firstly, S obtains $2 \mathrm{CP}$ and TV pairs $\left\{\mathrm{X}\left(\mathrm{h}_{1}\right), \mathrm{Q}\left(\mathrm{h}_{1}\right)\right\},\left\{\mathrm{X}\left(\mathrm{h}_{2}\right), \mathrm{Q}\left(\mathrm{h}_{2}\right)\right\}$, and constructs its message while attaching tag vector $\mathrm{Q}\left(\mathrm{h}_{2}\right)$ and its encrypted address $\mathrm{A}_{\mathrm{S}}$ to its sending message $M_{S}$ as shown in Fig. 5 (a). Namely, $\mathrm{S}$ constructs $M_{S}\left\|\mathrm{Q}\left(\mathrm{h}_{2}\right)\right\|\left(\mathrm{X}_{\mathrm{U}}\left(\mathrm{h}_{2}\right) \oplus \mathrm{A}_{\mathrm{S}}\right)$, concatenation of $M_{S}, \mathrm{Q}\left(\mathrm{h}_{2}\right)$, and $\mathrm{X}_{\mathrm{U}}\left(\mathrm{h}_{2}\right) \oplus \mathrm{A}_{\mathrm{S}}$. Where bit strings $\mathrm{X}_{\mathrm{U}}\left(\mathrm{h}_{2}\right)$ and $\mathrm{X}_{\mathrm{L}}\left(\mathrm{h}_{2}\right)$ are upper and lower parts of bit string $\mathrm{X}\left(\mathrm{h}_{2}\right)$, in other words, $\mathrm{X}\left(\mathrm{h}_{2}\right)=\mathrm{X}_{\mathrm{U}}\left(\mathrm{h}_{2}\right) \| \mathrm{X}_{\mathrm{L}}\left(\mathrm{h}_{2}\right)$. Also it is assumed that message $M_{S}$ includes its destination address at its left most bit positions.

After that, $\mathrm{S}$ encrypts $M_{S}\left\|\mathrm{Q}\left(\mathrm{h}_{2}\right)\right\| \mathrm{X}_{\mathrm{U}}\left(\mathrm{h}_{2}\right) \oplus \mathrm{A}_{\mathrm{S}}$ to $\mathrm{X}\left(\mathrm{h}_{1}\right) \oplus\left(M_{S}\left\|\mathrm{Q}\left(\mathrm{h}_{2}\right)\right\| \mathrm{X}_{\mathrm{U}}\left(\mathrm{h}_{2}\right) \oplus \mathrm{A}_{\mathrm{S}}\right), \quad$ and sends $\left\{\mathrm{X}\left(\mathrm{h}_{1}\right) \oplus\left(M_{S}\left\|\mathrm{Q}\left(\mathrm{h}_{2}\right)\right\| \mathrm{X}_{\mathrm{U}}\left(\mathrm{h}_{2}\right) \oplus \mathrm{A}_{\mathrm{S}}\right), \quad \mathrm{Q}_{1}\left(\mathrm{~h}_{1}\right), \quad \mathrm{Q}_{2}\left(\mathrm{~h}_{1}\right), \quad---\right.$ $\left.\mathrm{Q}_{\mathrm{N}}\left(\mathrm{h}_{1}\right)\right\}$ to the 1 st server $\mathrm{T}_{1}$ in the anonymous channel. Then, $\mathrm{T}_{1}$ decrypts it by $\mathrm{x}_{1}\left(\mathrm{~h}_{1}\right), \mathrm{CP}$ constructor of $\mathrm{T}_{1}$. As a result, the message becomes $\left\{\mathrm{x}_{1}\left(\mathrm{~h}_{1}\right) \oplus \mathrm{X}\left(\mathrm{h}_{1}\right) \oplus\left(M_{S}\left\|\mathrm{Q}\left(\mathrm{h}_{2}\right)\right\| \mathrm{X}_{\mathrm{U}}\left(\mathrm{h}_{2}\right) \oplus \mathrm{A}_{\mathrm{S}}\right), \quad \mathrm{Q}_{2}\left(\mathrm{~h}_{1}\right), \quad---\right.$ $\left.\mathrm{Q}_{\mathrm{N}}\left(\mathrm{h}_{1}\right)\right\}=\left\{\mathrm{x}_{2}\left(\mathrm{~h}_{1}\right) \oplus---\oplus \mathrm{x}_{\mathrm{N}}\left(\mathrm{h}_{1}\right) \oplus\left(M_{\mathrm{S}}\left\|\mathrm{Q}\left(\mathrm{h}_{2}\right)\right\| \mathrm{X}_{\mathrm{U}}\left(\mathrm{h}_{2}\right) \oplus \mathrm{A}_{\mathrm{S}}\right)\right.$, $\left.\mathrm{Q}_{2}\left(\mathrm{~h}_{1}\right),---, \mathrm{Q}_{\mathrm{N}}\left(\mathrm{h}_{1}\right)\right\}$. Each server $\mathrm{T}_{\mathrm{j}}$ in the anonymous channel carries out the same procedure until receiver $\mathrm{R}$ receives $M_{S}\left\|\mathrm{Q}\left(\mathrm{h}_{2}\right)\right\| \mathrm{X}_{\mathrm{U}}\left(\mathrm{h}_{2}\right) \oplus \mathrm{A}_{S}$. Then $\mathrm{R}$ can extract message $M_{S}$, encrypted address $\mathrm{X}_{\mathrm{U}}\left(\mathrm{h}_{2}\right) \oplus \mathrm{A}_{\mathrm{S}}$ of $\mathrm{S}$ and tag vector $\mathrm{Q}\left(\mathrm{h}_{2}\right)$ to construct its reply message as $\left\{\left(\mathrm{X}_{\mathrm{U}}\left(\mathrm{h}_{2}\right) \oplus \mathrm{A}_{\mathrm{S}}\right) \| M_{R}, \mathrm{Q}_{1}\left(\mathrm{~h}_{2}\right),---, \mathrm{Q}_{\mathrm{N}}\left(\mathrm{h}_{2}\right)\right\}$ to be encrypted to $\mathrm{X}\left(\mathrm{h}_{2}\right) \oplus\left\{\mathrm{X}_{\mathrm{U}}\left(\mathrm{h}_{2}\right) \oplus \mathrm{A}_{\mathrm{S}} \| M_{R}\right\}=\left\{\mathrm{A}_{\mathrm{S}} \| \mathrm{X}_{\mathrm{L}}\left(\mathrm{h}_{2}\right) \oplus M_{R}\right\}$, by the anonymous channel as shown in Fig. 5 (b). Therefore, $\mathrm{T}_{\mathrm{N}}$ can deliver $\mathrm{X}_{\mathrm{L}}\left(\mathrm{h}_{2}\right) \oplus M_{R}$ to $\mathrm{S}$ and finally $\mathrm{S}$ that knows $\mathrm{X}_{\mathrm{L}}\left(\mathrm{h}_{2}\right)$ decrypts $\mathrm{X}_{\mathrm{L}}\left(\mathrm{h}_{2}\right) \oplus M_{R}$ to $\mathrm{X}_{\mathrm{L}}\left(\mathrm{h}_{2}\right) \oplus \mathrm{X}_{\mathrm{L}}\left(\mathrm{h}_{2}\right) \oplus M_{R}=M_{R}$.

In the above, $\mathrm{R}$ receives $M_{S}\left\|\mathrm{Q}\left(\mathrm{h}_{2}\right)\right\| \mathrm{X}_{\mathrm{U}}\left(\mathrm{h}_{2}\right) \oplus \mathrm{A}_{\mathrm{S}}$, and it cannot know $A_{S}$ because $\mathrm{X}_{\mathrm{U}}\left(\mathrm{h}_{2}\right)$ is known only to $\mathrm{S}$. Also, message $\mathrm{X}_{\mathrm{U}}\left(\mathrm{h}_{2}\right) \oplus \mathrm{A}_{\mathrm{S}} \| M_{R}$ sent by $\mathrm{R}$ is transformed to $\mathrm{A}_{\mathrm{S}} \| \mathrm{X}_{\mathrm{L}}\left(\mathrm{h}_{2}\right) \oplus M_{R}$ in the anonymous channel, therefore, no one except $\mathrm{S}$ can know that $\mathrm{X}_{\mathrm{L}}\left(\mathrm{h}_{2}\right) \oplus M_{R}$ corresponds to $M_{R}$, and consequently even receiver $\mathrm{R}$ that knows $M_{R}$ cannot identify the original sender of $M_{S}$. In this way, servers in ESEBM can handle original and reply messages totally in the same way, different from usual Mixnets where each mixserver adds extra operations on reply messages.

\section{Evaluation OF EsEBM}

\section{A. Analysis of ESEBM Behavior}

ESEBM satisfies the requirements for anonymous networks listed in Sec. II as follows. Firstly as discussed in Sec IV. C, no one except senders themselves can trace messages from senders to receivers. Secondly, the message reply mechanism discussed in Sec. V enables receivers to send replies to senders of original messages without knowing identities of the senders. Also by this reply mechanism, senders can confirm the deliveries of their messages. In addition the reply mechanism of ESEBM does not require additional operations on reply messages, therefore different from other existing anonymous networks, servers cannot know even whether their handling messages are replies or not.

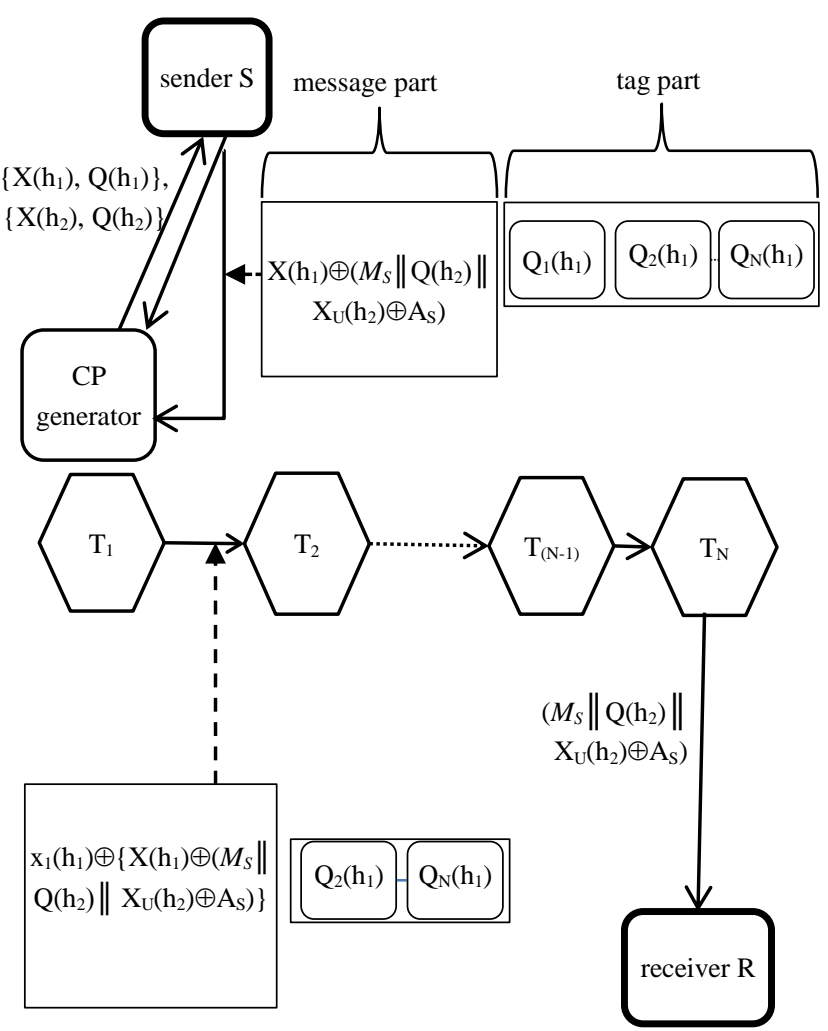

(a) From sender to receiver

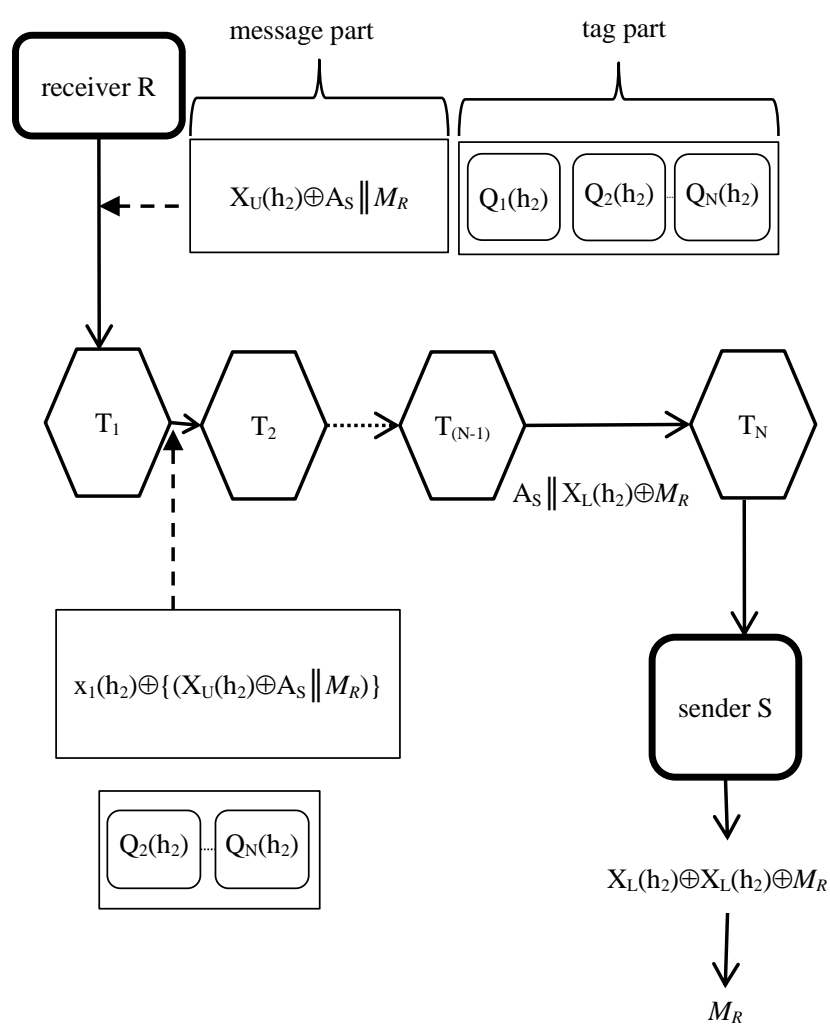

(b) From receiver to sender

Figure 5. Anonymous reply mechanism 
About the efficiency, the configuration of ESEBM where senders must obtain CPs before sending their individual messages is obviously a disadvantage, e. g. message travelling times increase when durations required for obtaining CPs are counted. However because senders can obtain CPs as offline processes, actual message traveling times can be suppressed at values comparable to Mixnet. Also, when each server is configured by 2 independent CPUs, tasks for generating CPs and forwarding messages can be assigned to different CPUs so that the anonymous channel can forward messages without being interrupted by tasks for the $\mathrm{CP}$ generator. Then, despite of the disadvantages of the CP obtaining process, ESEBM configuration enables anonymous networks to adopt symmetric key encryption functions that make ESEBM efficient enough as usual non-anonymous networks to handle messages in practical scale applications as demonstrated in the next subsection.

ESEBM configuration brings advantageous features not only about the efficiency but also about security as follows. Among various threats to networks, DOS attacks [10], in which meaningless or spam messages are sent to decrease availabilities of networks, and illegitimate message forgeries (modifications), in which malicious entities forge (modify) messages sent from anonymous senders, are especially serious in anonymous networks. Different from in usual networks where all entities that send messages can be identified if costs and efforts are not considered, in anonymous networks where identities of senders are completely hidden, entities can behave dishonestly more easily. In addition, about message forgeries (modifications), in many cases receivers cannot notice even if their receiving messages are forged (modified) because their senders are anonymous.

The CP generator in ESEBM reduces the occurrence of DOS attacks substantially and makes forged (modified) messages detectable. Namely, senders must attach consistent TVs to their messages to let servers transfer the messages; however, the CP generator gives CPs and TVs only to authorized entities. Therefore, unauthorized entities must send their messages while attaching nonregistered TVs, and servers in ESEBM that cannot find CPs and TVs from their CP tables discard the messages immediately, as the consequence, messages from unauthorized entities do not decrease the availability of the network. About the malicious message forgeries (modification), provided that the malicious entity $\mathrm{X}$ does not know the original message $M, \mathrm{X}$ cannot forge (modify) encrypted $M$ consistently because no one except the sender of $M$ knows the CP used for encrypting $M$, then the receiver of $M$ can notice the forgeries (modification) because its receiving message is meaningless.

In the same way, ESEBM disables entities to carry out traffic analysis attacks and replay attacks. A traffic analysis attack is a way to identify the sender $\mathrm{S}$ of a message $M$ by sending multiple replies to it [7, 14]. Namely, when receiver $\mathrm{R}$ of $M$ sends many replies at a time or periodically to $\mathrm{S}, \mathrm{R}$ can identify $\mathrm{S}$ by observing entities that receives many messages at a time or periodically. However, in ESEBM every message must have different CPs and TVs, and this means that every server discards CP and TV constructors in its CP table once they are used. Therefore, provided that at least one of the servers is honest, even when $\mathrm{R}$ sends multiple replies only one of them is delivered to $\mathrm{S}$, and R cannot identify $\mathrm{S}$. It must be noted that, it is also possible to enable receivers to send up to predefined number of replies. If each server $T_{j}$ maintains $F(h)$, the number of messages allowed to send by using tag vector $\mathrm{Q}(\mathrm{h})$, in its $\mathrm{CP}$ table in addition to $\left\{\mathrm{x}_{\mathrm{j}}(\mathrm{h}), \mathrm{q}_{\mathrm{j}}(\mathrm{h})\right\}, \mathrm{T}_{\mathrm{j}}$ does not invalidate $\left\{\mathrm{x}_{\mathrm{j}}(\mathrm{h})\right.$, $\left.\mathrm{q}_{\mathrm{j}}(\mathrm{h})\right\}$ until it receives $\mathrm{F}(\mathrm{h})$-messages attached by $\mathrm{Q}(\mathrm{h})$.

In a replay attack [11], an entity $\mathrm{X}$ identifies sender $\mathrm{S}$ of message $M$ by eavesdropping on the network to pick $M_{*}$, encrypted form of $M$, just sent from $\mathrm{S}$, and putting $M_{*}$ to the network repeatedly. Then, because $M$ is delivered to the same receiver $\mathrm{R}$ many times, $\mathrm{X}$ can easily identify the correspondence between $\mathrm{S}$ and $M$ received by $\mathrm{R}$. Apparently ESEBM can disable replay attacks in the same way as disabling traffic analysis attacks.

\section{B. Message Processing Performance}

Performance of ESEBM has been compared with that of the usual non-anonymous networks and Mixnet each of which consisted of multiple PCs that worked as relay servers. Where individual PCs were equipped with 1.6GHz CPUs and 1GB of RAM and they were connected by $100 \mathrm{Mbits} / \mathrm{sec}$ Ethernet. Because delays of message arrivals depend on the number of relay servers and the time that individual servers must wait for shuffling messages, only the throughput were compared while changing the sizes of messages. For evaluating ESEBM, 16 tags each of which consisted of 64 bits were attached to individual messages, therefore for ESEBM, the actual length of a $10 \mathrm{Kbits}$ message is $11 \mathrm{Kbits}$ for example. For Mixnet, RSA with $1 \mathrm{~K}$ bits length key was adopted as the encryption function. In real applications, a sender must combine its message $M$ with random secret numbers to make the encryption function probabilistic. Also to maintain strengths of encryption keys, different servers must use different modulo arithmetic. However in this evaluation, random bit strings were not attached to messages, and all servers used the same modulo arithmetic.

Table 1 shows the computation times required by each server in non-anonymous network, ESEBM and Mixnet to transfer different sizes of messages, and Fig. 6 graphically represents them. For example, while ESEBM needs less than 6 seconds to transfer a 20Mbits message, Mixnet needs more than 3 minutes to transfer the same message. Fig. 7 shows the volume of messages that usual non-anonymous networks, ESEBM and Mixnet can send within 1 second. These results show that, although the throughput of ESEBM is $1 / 4.4$ of that of non-anonymous networks, it is more than 36 times higher than that of Mixnet. According to statistics [16], e-mail message size is $59 \mathrm{~KB}$ on average, therefore, even in the environments used for evaluations, ESEBM can handle 7 clients at a time that send usual e-mail messages while the non-anonymous network can handle 33 clients at a time. On the other hand, Mixnet can handle only 0.2 clients. The beneficial thing is that, when multiple processors are 
available, volume of messages can be processed almost in parallel. Therefore, ESEBM can transfer the same volume of messages as usual non-anonymous networks do when each server is constituted by multiple processors and memories with 4.4 times of costs. Here, although it depends on individual applications, value 4.4 can be considered acceptable. On the other hand, to improve the performance of Mixnet as non-anonymous networks, 158 times of costs are necessary. Namely, ESEBM can be used for large scale networks, in which number of clients exchange usual sizes of messages at less extra costs.

TABLE I. COMPUTATION TIME FOR TRANSFERRING DIFFERENT SIZES OF MESSAGES

\begin{tabular}{|c|c|c|c|}
\hline $\begin{array}{c}\text { Message size } \\
\text { Mbits }\end{array}$ & $\begin{array}{c}\text { Non-anonymous } \\
(\mathrm{msec})\end{array}$ & $\begin{array}{c}\text { ESEBM } \\
(\mathrm{msec})\end{array}$ & $\begin{array}{c}\text { Mixnet } \\
(\mathrm{msec})\end{array}$ \\
\hline 10 & 625 & 2780 & 105255 \\
\hline 20 & 1230 & 5510 & 207440 \\
\hline 30 & 1924 & 8556 & 310986 \\
\hline 40 & 2520 & 11225 & 412679 \\
\hline 50 & 3125 & 14127 & 528276 \\
\hline 60 & 3745 & 17342 & --- \\
\hline 70 & 4325 & 19710 & --- \\
\hline 80 & 4995 & 22862 & --- \\
\hline 90 & 5643 & 25595 & --- \\
\hline 100 & 6246 & 28344 & --- \\
\hline
\end{tabular}

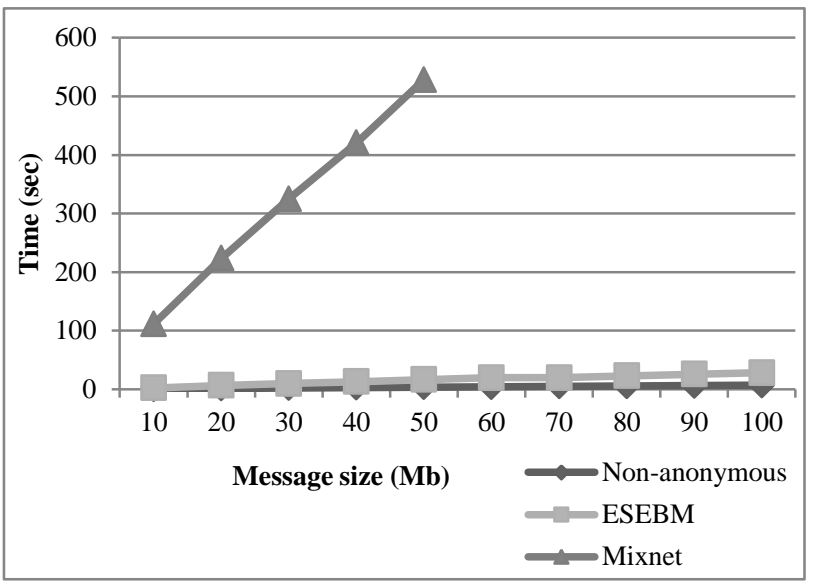

Figure 6. Comparison of computation time for transferring different sizes of messages

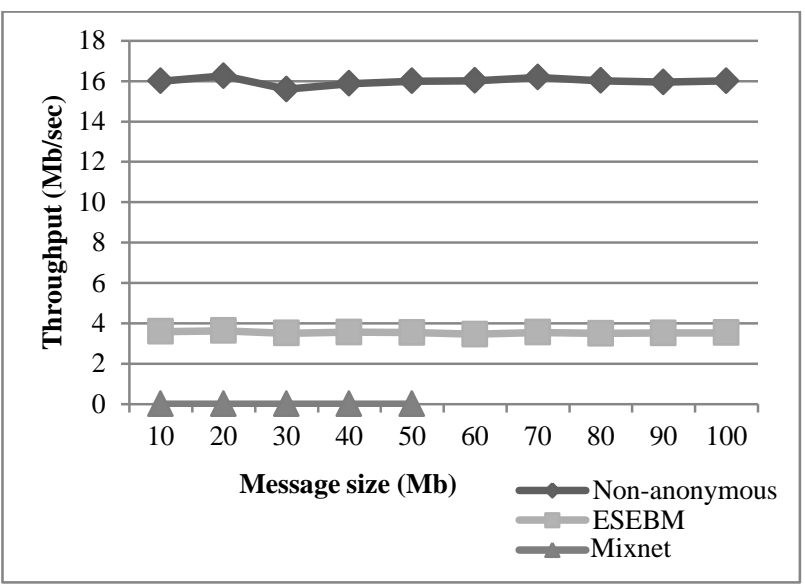

Figure 7. Comparison of throughputs for transferring different sizes of messages
About the breakdown of message processing time of each server in ESEBM, it consists of shuffling (31\%), message decryption (26\%), and others (43\%). On the other hand, message processing time of each server in Mixnet consists of shuffling $(0.8 \%)$, message decryption $(98.6 \%)$, and others $(0.6 \%)$. As shown above, different from Mixnet in which message decryptions require 123 times of message shuffling time, in ESEBM, message decryptions require less than 0.84 times of the shuffling time. When the fact that both ESEBM and Mixnet shuffle same number of messages is considered, this means that message decryption process in Mixnet degrades its overall performance seriously. In other words, symmetric key encryption functions used in ESEBM had successfully reduced decryption times. Namely, while RSA used in Mixnet requires the number of multiplications that is proportional to $\log _{2}(n)$, onetime pad used in ESEBM requires only a single XOR operation, where $n$ is the size of encryption keys.

SEBM also uses symmetric key encryption functions [13], and as ESEBM, it can achieve the higher throughput than other anonymous networks such as Mixnet. However, when compared with ESEBM, in SEBM, more servers must be involved in forwarding messages, because it consists of encryption and decryption servers. Therefore, message traveling times in SEBM become longer than that of ESEBM, i.e. different from in ESEBM where messages are encrypted by their senders, in SEBM, they are encrypted by a sequence of encryption servers. As other advantages of ESEBM over SEBM, ESEBM works more stably because all servers in ESEBM are permanent servers different from SEBM where senders are included as servers. Also a mechanism for reply messages is not straightforward in SEBM.

\section{CONCLUSION}

Enhanced symmetric key encryption based Mixnet has been proposed that removes the drawbacks of many existing anonymous networks such as Mixnet, DC-net, etc. It satisfies all the requirements of anonymous networks. Most importantly, while being supported by concealing patterns, those requirements are satisfied in a simple and efficient way. Unlike complicated Mixnet based systems, the simplified computational requirements of individual entities make the scheme practical and scalable.

As a drawback of ESEBM, a sender must acquire a concealing pattern from the $\mathrm{CP}$ generator in advance to send its every message as an offline process. However because of ESEBM configuration, i.e. by dividing the network into the $\mathrm{CP}$ generator (off-line) and the anonymous channel (on-line) parts, every time-consuming task is removed from the anonymous channel part and highly efficient communication becomes possible. Moreover, concealing patterns enable receivers not only to send replies to the original anonymous message senders but also to receive messages without disclosing their identities. Namely, when concealing patterns are publicly disclosed with the receivers' interests, the receivers can receive messages from senders without disclosing their identities.

As a future work, mechanisms that enhance the 
reliability of ESEBM are necessary. When senders or receivers claim that some server is dishonest, ESEBM must prove all servers are honest or detect dishonest servers if exist. Also, ESEBM must continue its operations even some of servers are out of their services.

\section{REFERENCES}

[1] D. Chaum, "Untraceable electronic mail, return address and digital pseudonyms," Communications of the ACM, vol. 24, no. 2, pp. 84-88, 1981.

[2] D. Chaum, "The dining cryptographers problem: unconditional sender and recipient untraceability," Journal of Cryptology, vol. 1, pp. 65-75, 1988.

[3] M. G. Reed, P. F. Syverson and D. M. Goldschlag, "Anonymous connections and onion routing," Selected Areas in Communications, vol. 16, no. 4, pp. 482-494, May 1998.

[4] M. K. Reiter and A. D. Rubin, "Crowds: anonymity for Web transactions," ACM Transactions on Information and System Security, vol. 1, no. 1, pp. 66-92, Nov 1998.

[5] R. Ingledine, M. J. Freedman, D. Hopwood and D. Molnar, "A reputation system to increase MIX-Net reliability," Proc. of the 4th international Workshop on information Hiding. I. S. Moskowitz, Ed. Lecture Notes In Computer Science, Springer-Verlag, vol. 2137, London, pp. 126-141, April 2001.

[6] A. Beimel and S. Dolev, "Buses for anonymous message delivery," Proc. of the Second International Conference on FUN with Algorithms, Elba, Italy, pp. 1-13, May 2001

[7] P. Golle and M. Jakobsson, "Reusable anonymous return channels," Proc. of the 2003 ACM Workshop on Privacy in the Electronic Society, (Washington, DC), WPES '03, ACM, New York, NY, pp. 94-100, 2003.

[8] R. Dingledine and N. Mathewson, "Tor: The second-generation onion router," Proc. of the 13th USENIX Security Symposium, San Diego, CA, USA, pp. 303-320, August 2004.

[9] P. Golle, M. Jakobsson, A. Juels and P. Syverson, "Universal re-encryption for Mixnets," RSA Conference Cryptographers' Track '04, Springer-Verlag, pp. 163-178, 2004.

[10] T. Znati, J. Amadei, D. R. Pazehoski and S. Sweeny, "On the design and performance of an adaptive, global Strategy for detecting and mitigating distributed DOS attacks in GRID and collaborative workflow environments," Simulation, vol. 83, pp. 291-303, March 2007.

[11] S. Y. Kang, J. S. Park and I. Y. Lee, "A study on authentication protocol in offering identification synchronization and position detection in RFID system," Proc. of The 2007 International Conference on Intelligent Pervasive Computing (IPC 2007), pp. 150-154, 2007.

[12] X. Wang and J. Luo, "A collaboration scheme for making peer-to-peer anonymous routing resilient," Computer Supported Cooperative Work in Design, 2008, CSCWD 2008, pp. 70-75, April 2008.

[13] S. Tamura, K. Kouro, M. Sasatani, K. M. Alam and H. A. Haddad, "An information system platform for anonymous product recycling," Journal of Software, vol. 3, no. 6, pp. 46-56, 2008

[14] L. Li, S. Fu and X. Che, "Active attacks on reputable Mix Networks," ispa, 2009 IEEE International Symposium on Parallel and Distributed Processing with Applications, pp. 447-450, 2009.

[15] H. Haddad, H. Tsurugi and S. Tamura, "A mechanism for enhanced symmetric key encryption based Mixnet," SMC 2009 IEEE International Conference on Systems, Man and

Cybernetics, San Antonio, TX, USA, pp. 4541-4546, 11-14 Oct 2009, doi: 10.1109/ ICSMC.2009.5346788.

[16] http://www.idc.com/

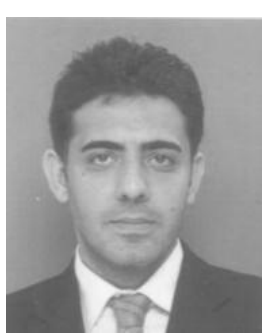

Hazim A. Haddad received the B.E. degree in Computer science and Engineering from Ittihad University, from UAE (United Arab Emirates) in 2003, M.S. degree in nuclear and safety engineering, from the University of Fukui in 2008. He is currently a doctor course student of University of Fukui.

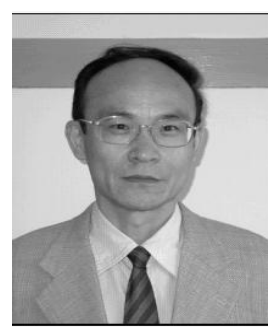

SICE and JSST.

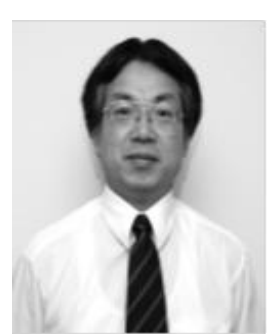

Shuji Taniguchi received the B.E. and Ph.D. degrees in electronics engineering from University of Fukui, Fukui, Japan, in 1973, 1996, respectively. In 1973-1978, he was with the Hitachi co. Ltd. He is currently an associate professor of Graduate School of Engineering in University of Fukui.

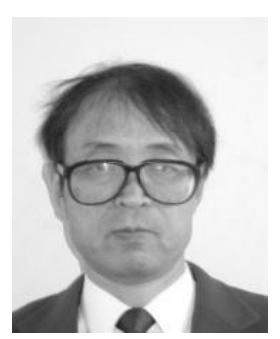

Tatsuro Yanase received the Dr. (Eng.) degrees in Electric \& Electronic Engineering from Nagoya University in 1977. During 1967 to 1969 he worked for Nippon Calculating Machine Corporation. $\mathrm{He}$ is now an associate professor of Graduate School of Engineering, University of Fukui. 